\title{
EXISTING CONDITION AND PROSPECTS OF MAKING POWER BALANCE AND MANAGING LOAD OF ELECTRIC CONSUMERS IN UZBEK POWER SYSTEM
}

\author{
${ }^{1} \mathrm{~K}$ M Reymov, ${ }^{2} \mathrm{G}$ R Rafikova, ${ }^{3} \mathrm{~L}$ A Nematov, ${ }^{1}$ Sh Esemuratova \\ ${ }^{1}$ Karakalpak State University, Nukus, Republic of Uzbekistan. \\ ${ }^{3}$ Bukhara engineering technological institute, associate professor of the department of Power Eninineering, DSc, \\ Uzbekistan, Bukhara region, 200100, Bukhara, street Murtazaev, 15 \\ ${ }^{2}$ Tashkent State Technical University named after Islam Karimov, Uzbekistan
}

\begin{abstract}
The possibilities and the effectiveness of using various methods of controlling the loads of electric consumers are determined with the conditions of the balance of capacities and electricity in the power system. In this regard, the article analyzes the current state and assesses the immediate prospects for ensuring a balance of capacities and electricity in the energy system of the Republic of Uzbekistan.
\end{abstract}

Electricity demand of economic sectors and the population is determined by the level of economic development and, to a large extent, by the efficiency of energy use and energy saving. These factors are interconnected and together form possible ways of socio-economic development. However, under any scenario of development, the main thing remains the formation of optimal proportions and structure of the power industry development as the determining and dominant sector of the country's economy.

The main consumers of electricity do not change for the near future, that is, they will be industry, agriculture and housing and communal sector. It should be taken into account that electric and heat power industry have high investment inertia and high capital intensity, it is undesirable that they become serious limitations of economic growth [1-5].

In the conditions of Uzbekistan it is necessary to intensify the use of solar energy, including for the purpose of "accumulation" of energy in batteries. In "scientific" energy sector there is a tendency to increase specific cost of electric power at hydraulic (HPS) and thermal power plants and counter reduction of cost of electric power at solar power plants. This trend should be carefully weighed, especially when it comes to small mountainous villages. And since any mountain village does not live without a nearby source of clean mountain water, there is a natural idea of a compact hydroelectric generator for $15-20$ kilowatts, which would rotate on the local hydroelectric system.

Apparently, it would be expedient to consider several projects to construct relatively small hydro accumulating power plants (HPPs) that, without harming the environment, may become helpers in creating centers of culture, tourism and recreation [7$11]$.
Now let us focus on the largest, in our opinion, project of energy production and conservation development in the country. Let us immediately note that it has two stages of depth of coverage.

At the first stage, order is being established in the most unified energy system of Uzbekistan. Some components of commercial losses are excluded. Order is established in the process of regimes maintenance, energy losses in transmission and distribution networks are minimized, generated capacity is optimized.

On the second stage, control penetrates into the environment of energy consumers themselves: whether the production technologies they use are good, whether they are not too energy consuming, whether they harm the environment, etc.

The world practice shows that for the electric power system (EPS) itself, the best generation schedule is direct and practically horizontal line. Such a loading line for the generating capacities of the power system is good because the working generators of thermal power plants do not stop and start up after the breaks, but work evenly, without accelerated wear and tear, without additional heat-ups for restarts. Start-ups and shutdowns are assigned to hydro generators "powered" from reservoirs and specially for this purpose.

One way remains promising - to address the large industrial power consumers with a proposal to become regulated electric consumers. In this case, there are two possible ways of transition from conventional (currently existing) power consumers to regulated power consumers [12-16].

In the forecasts of 2008 , the development of electric power industry of Uzbekistan was supposed on the scale ensuring self-balanced power system with possibility of transfer of energy outside the country, indicators of this forecast are presented in Table 1. 
Table 1. Prospects of power consumption development in Uzbekistan (Teshabayev, 2008)

\begin{tabular}{|l|l|c|c|c|}
\hline \multicolumn{1}{|c|}{ Nome } & \multicolumn{1}{|c|}{$\mathbf{2 0 1 5}$ year } & $\mathbf{2 0 2 0}$ year & $\mathbf{2 0 2 5}$ year \\
\hline 1 & Electricity consumption (billion kWh) & 56,0 & 61,8 & 68,25 \\
\hline 2 & Average annual growth rate (\%) & 2,0 & 2,0 & 2,0 \\
\hline 3 & Number of hours of maximum load usage (hour) & 6000 & 6100 & 6300 \\
\hline 4 & Maximum load (MW) & 9330 & 10130 & 10830 \\
\hline
\end{tabular}

We believe that the previous forecasts on commissioning of generating capacities in Uzbekistan's EES, presented in Table 2, should be carefully considered.
Of interest are also impressive plans to commission three new HPPs (Allayev, 2009): Pskem - $404 \mathrm{MW}$, Mullalak - $240 \mathrm{MW}$, Akbulak - $100 \mathrm{MW}$ and a number of small HPPs.

Table 2. Input of generating capacities in Uzbekistan, MW (Teshabayev, 2008)

\begin{tabular}{|c|c|c|c|}
\hline Introduced incl. & $\begin{array}{c}2009-2020 \\
\text { years. }\end{array}$ & $\begin{array}{c}2021-2025 \\
\text { years. }\end{array}$ & Total \\
\hline HPS & 529 & 386 & 915 \\
\hline PGI & 2046 & 1097 & 3143 \\
\hline GTI & 166 & 0 & 166 \\
\hline Total & $\mathbf{2 7 4 1}$ & $\mathbf{1 4 8 3}$ & $\mathbf{4 2 2 4}$ \\
\hline
\end{tabular}

Uzbekistan has not lost its significance today. The elements of this program themselves have retained their value:

- regulation of the load schedule using loads regulators, stimulating the compaction and "leveling" of the load schedule of the power system;

- tightening of the load schedule, which should occur gradually as differentiated tariffs for electricity are introduced;

- reducing the total losses of electricity, which at present and in the future is a very effective means of increasing the energy efficiency of EPS.

The power and energy balances of the Uzbek power system were analyzed as of March 16, 2015.

Fig. 1, 2 and 2a show a typical daily graph of the total load and generation of the power system of Uzbekistan.

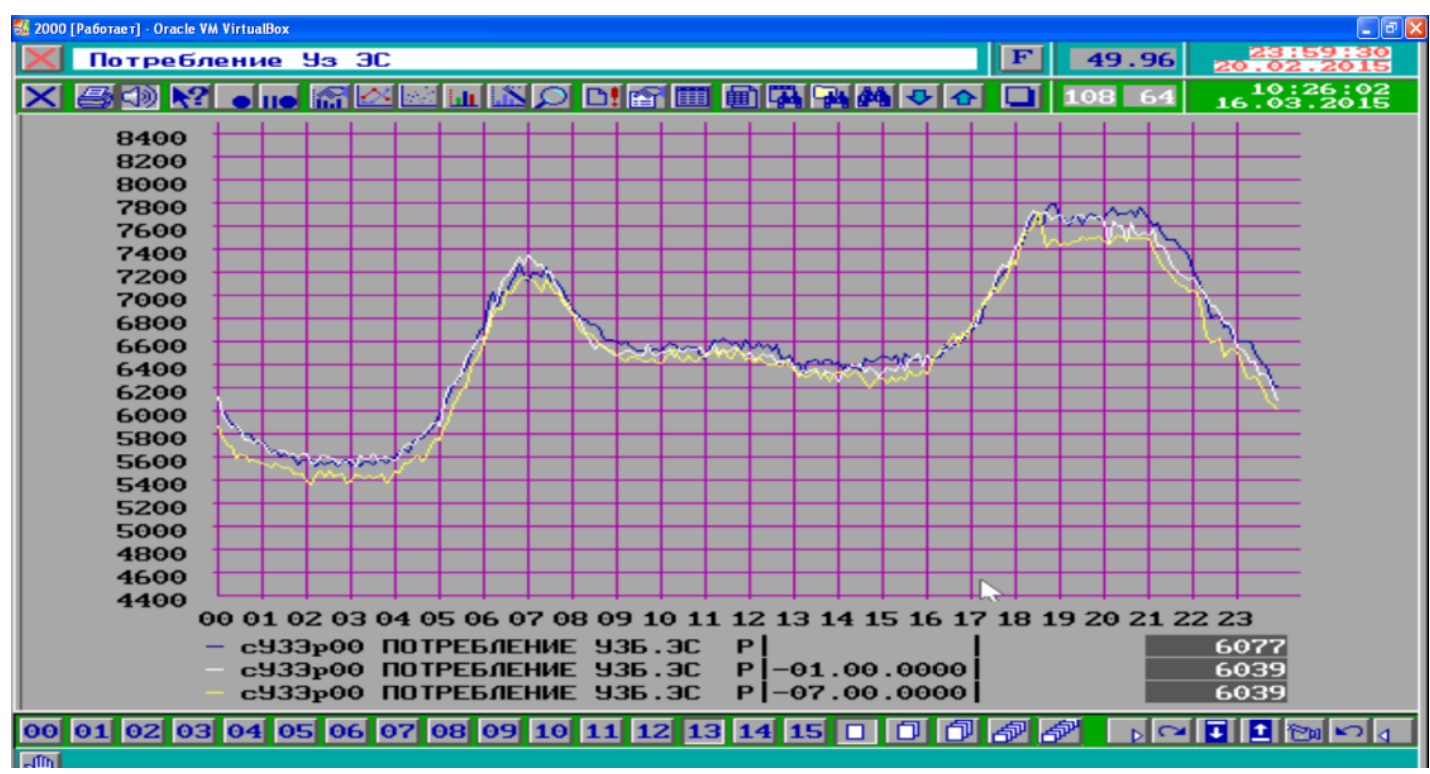

Fig. 1. The total load schedule (MW) of the power system of the Republic Uzbekistan as of 16.03.2015 


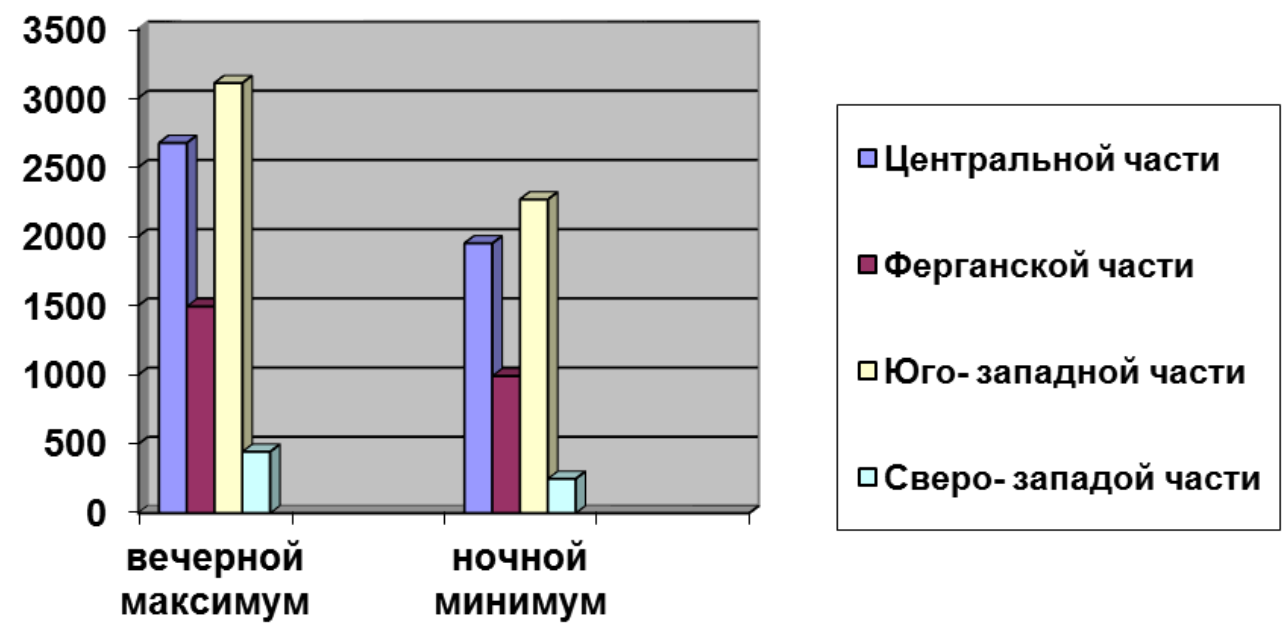

Fig. 2. Power consumption (MW) in the energy system of the Republic of Uzbekistan as of March 16, 2015
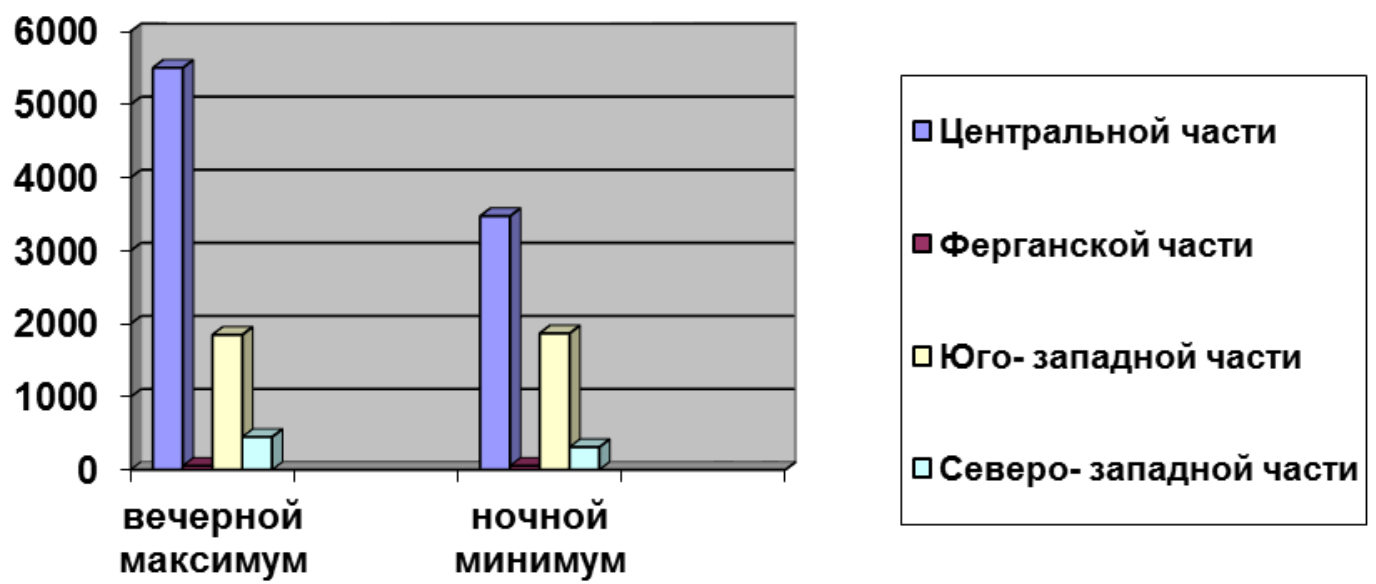

Fig. 2a. Power generation (MW) in the energy system of the Republic of Uzbekistan as of March 16, 2015

The balance of capacities is provided mainly due to its generation at our own power plants. On the day in question (March 16, 2015), the maximum consumption was $7800 \mathrm{MW}$, exports to Afghanistan - $300 \mathrm{MW}$ and generation - $7850 \mathrm{MW}$. At the same time, the balance of power flow amounted to $7850-(7800+300)=-250 \mathrm{MW}$, which means when passing the evening maximum, the energy system of Uzbekistan received $250 \mathrm{MW}$ from the United Energy System of Central Asia (UES CA) and exported $300 \mathrm{MW}$ of power to Afghanistan [17-21].

The reception of the regulating power occurs due to the limitations of fossil fuel (gas, heating oil and coal) or due to the lack of available capacity at power plants, especially in repair modes or during emergency shutdowns of powerful power units.

It was revealed that the power system has a sharply variable daily load schedule, which affects the efficiency of work. The range of variation of the daily load on the power system is:

For the winter season 5100-7850 MW;

For the flying season 5000-7300 MW.

Thus, the fluctuations of the total load in such a large range make it very difficult to cover the load schedule of the power system and make it necessary to manage its loads. Generation of the main part of electricity at thermal power plants $(80-85 \%)$, which are clearly inferior to hydroelectric plants in terms of maneuverability, makes this task even more difficult [22-25].

The analysis of the current state of power management shows that both in winter and summer the fluctuations of the total load during the day in the power system are partially covered by the balance of capacity flows, mainly through the overhead lines connecting the power systems of the Republic with the power systems of neighboring countries [26-29].

Thus, the need to manage electricity consumption in the energy system of Uzbekistan is dictated by a number of reasons, the most important of which are the following:

- Significant difference between night minimum and peak load in the power system;

- insufficient regulation range of thermal power plants for their participation in the variable part of the resulting load schedule;

- technical and economic inexpediency of frequent changes in the composition of operating units at thermal power plants; 
- practical lack of reserves of maneuverable capacities in the power system; - limited capacity of electric networks.

\section{References}

1. Taslimov, A.D., Rakhmonov, I.U. (2019) Optimization of complex parameters of urban distribution electric networks Journal of Physics: Conference Series 1399 doi:10.1088/17426596/1399/5/055046

2. Rakhmonov, I.U., Niyozov, N.N. (2019) Optimization setting of steel-smelting industry in the issue of alloy steels $E 3 S$ Web Conf 139 doi:10.1051/e3sconf/201913901077

3. Rakhmonov, I.U., Reymov, K. M., Shayumova, Z.M. (2019) The role information in power management tasks. E3S Web Conf 139 doi: $10.1051 / \mathrm{e} 3$ sconf $/ 201913901080$

4. Rakhmonov, I.U., Reymov, K.M. (2019) Mathematical Models and Algorithms of Optimal Load Management of Electricity Consumers J ENERGETIKA. Proceedings of CIS higher education institutions and power engineering association 62(6) pp 528-535 doi:10.21122/1029-7448-2019-62-6-528-535 5. Rakhmonov, I. U., Tovbaev, A.N., Nematov, L.A., Alibekova,T.Sh. (2020) Development of forecasted values of specific norms for the issues of produced products in industrial enterprises Journal of Physics: Conference Series 1515 doi:10.1088/1742-6596/1515/2/022050

6. Rakhmonov, I.U., Nematov, L.A., Niyozov, N.N, Reymov, K.M., Yuldoshev, T.M. (2020) Power consumption management from the positions of the general system theory Journal of Physics: Conference Series 1515 doi:10.1088/17426596/1515/2/022054

7. Rakhmonov, I.U., Reymov, K.M., Najimova, A.M., Uzakov, B.T., Seytmuratov, B.T. (2019) Analysis and calculation of optimum parameters of electric arc furnace Journal of Physics: Conference Series 1399 doi:10.1088/1742$6596 / 1399 / 5 / 055048$

8. Rakhmonov, I.U., Reymov, K.M. (2019) Regularities of change of energy indicators of the basic technological equipment of the cotton-cleaning industry Journal of Physics: Conference Series 1399 doi:10.1088/1742-6596/1399/5/055038 9. Rakhmonov, I. U., Reymov, K.M., Dustova, S.H. (2020) Improvements in industrial energy rationing methods Journal of IOP: Conference Series. MIP: Engineering-2020. 862 (2020) 062070 doi:10.1088/1757-899X/862/2/062070

10. Rakhmonov, I.U., Berdishev, A.A., Niyozov, N.N., Muratov, A., Khaliknazarov U. (2020) Development of a scheme for generating the predicted value of specific electricity consumption Journal of IOP: Conference Series. MIP: Engineering-2020. 883 (2020) 012103 doi:10.1088/1757$899 \mathrm{X} / 883 / 1 / 012103$

11. Rakhmonov, I.U., Berdishev, A.A., Khusanov, B.M., Khaliknazarov, U., Utegenov, U. (2020) General characteristics of networks and features of electricity consumers in rural areas Journal of IOP: Conference Series. MIP: Engineering-2020. 883 (2020) 012104 doi:10.1088/1757-899X/883/1/012104

12. Hoshimov, F.A., Bakhadirov, I.I., Erejepov, M., Djumamuratov, B. (2019) Development of method for normalizing electricity consumption E3S Web Conf 139 doi:10.1051/e3sconf/201913901074

13. Karimov R.Ch., Bobojanov M.K., Rasulov A.N., Usmanov E.G. E3S Web of Conferences, 139, 01039, (2019), doi.org/10.1051/e3sconf/201913901039;

14. Karimov R.Ch., Shamsiyev K., and others. IOP Conf. Series: Materials Science and Engineering, 883(1), 012142, (2020). doi:10.1088/1757-899X/883/1/012142;

15. E.G.Usmanov, A.N.Rasulov, M.K.Bobojanov, R.Ch.Karimov. E3S Web of Conferences 139, 01079 (2019), doi.org/10.1051/e3sconf/201913901079;
16. Karimov R.Ch., Shamsiyeva N. and others. IOP Conf. Series: Materials Science and Engineering, 883(1), 012120, (2020). doi:10.1088/1757-899X/883/1/012120

17. G.R.Rafikova, M.R.Ruzinazarov, S.K.Makhmutkhonov. E3S Web of Conferences, 139, 01075, (2019), https://doi.org/10.1051/e3sconf/201913901075

18. Khakimov,H.T., Shayumova,Z.M., Kurbanbaeva,Z.K., Khu sanov,B.M. Development of optimal modes and mathematical models of energy performance of electric steelmaking production//E3S Web of Conferences, 2019, 139, 01076

19. Khushnud Sapaev and Shukhrat Umarov. Two approaches for automating analysis of electromagnetic processes in nonlinear circuits with valves. Web of Conferences https://doi.org/10.1051/e3sconf/20191390 E 3S 139 (2019) 10 1085 RSES 20198

20. Allayev, K.R., Fedorenko, G.M.,Postnikov, V.I.,Ostapchuk, L.B. Asynchronous generators as power system's natural dampers. 43rd International Conference on Large High Voltage Electric Systems 2010, CIGRE 20102010, 9p43rd International Conference on Large High Voltage Electric Systems 2010, CIGRE 2010; Paris; France; 22 August 2010.

23. Fazylov, Kh.F.,Allaev, K.R. Analysis of the operation of an electrical system during simultaneous operation of synchronous and asynchronous generators. Power engineering New York Volume 18, Issue 3, 1980, Pages 81-88.

26. Fazylov, Kh.F.,Allaev, K.R. Asynchronous turbogenerators with stator excitation and the prospects for their utilization. Power engineering New York Volume 23, Issue 2, 1985, Pages 7-13.

29. Fazylov, Kh.F.,Allaev, K.R. Calculation and experimental analysis of conditions of electrical power systems containing induction generators Power Engineering New York Volume 27, Issue 6, 1989, Pages 27-34. 